\title{
ANALISIS RESETTING RELE JARAK AKIBAT UPRATING KONDUKTOR GIS PESANGGARAN - GI SANUR
}

\author{
Rizal Akbar Fauzany ${ }^{1}$, I Gede Dyana Arjana ${ }^{2}$, Cok Gede Indra Partha ${ }^{3}$ \\ ${ }_{1,2,3}$ Program Studi Tdeknik Elektro, Fakultas Teknik, Universitas Udayana \\ Email : rizalfaufauz@gmail.com ${ }^{1}, \underline{\text { dyanaariana@unud.ac.id }}{ }^{2}, \underline{\text { cokindra@unud.ac.id }}{ }^{3}$
}

\begin{abstract}
Abstrak
Meningkatnya arus beban pada saluran Pesanggaran - Sanur sebesar 333,536 Ampere atau 83,384 \% dari kuat hantar arusnya menyebabkan diperlukannya uprating konduktor dari ACSR Partridge $135 \mathrm{~mm} 2$ menjadi ACCC Lisbon $310 \mathrm{~mm} 2$. Uprating menyebabkan perubahan nilai impedansi. Perubahan ini mempengaruhi jangkauan zona proteksi rele jarak GIS Pesanggaran - GI Sanur sehingga saling tumpang tindih dengan zona proteksi rele jarak GI Sanur - Gl Gianyar. Resetting dilakukan dengan menghitung ulang nilai impedansi sesuai kaidah pengaturan rele jarak dan hasilnya diuji dengan gangguan hubung singkat pada jarak 86 \% saluran Pesanggaran - Sanur. Resetting menghasilkan nilai impedansi baru yang membuat rele bekerja sesuai dengan standar IEEE Std C37.113-2015.
\end{abstract}

Kata kunci :Sistem Proteksi, Uprating, Resetting, Rele Jarak.

\begin{abstract}
Increased load current on the Pesanggaran - Sanur transmission line by 333,536 Ampere or $83,384 \%$ of the current carrying capacity caused the uprating conductor from ACSR Partridge $135 \mathrm{~mm} 2$ into ACCC Lisbon $310 \mathrm{~mm} 2$. Uprating cause changes in impendance value. This change affects the zone reach protection of GIS Pesanggaran - GI Sanur distance relay which overlaps with Zone protection of GI Sanur - GI Gianyar distance relay. Resetting is done by recalculation according the distance relay rules and the result are tested with short circuit at $86 \%$ Pesangaran - Sanur transmission line. Resetting result shows the distance relay operate appropriately according with the IEEE Standard C37.113-2015.
\end{abstract}

Keywords: Protection System, Uprating, Resetting, Distance Relay.

\section{PENDAHULUAN}

Provinsi Bali sebagai daerah destinasi wisata dunia memiliki pertumbuhan ekonomi sebesar 5,27 \%. Pertumbuhan ini berbanding lurus dengan tingginya pertumbuhan jumlah pelanggan PLN sebesar 4,29\% dan pertumbuhan penjualan energi sebesar $6,83 \%$. Hal ini disebabkan pergeseran struktur ekonomi daerah Bali yang sebelumnya didominasi oleh sektor pertanian menjadi sektor perdagangan, restoran, properti, dan hotel [1]. Pergeseran struktur ekonomi tersebut meningkatkan kebutuhan konsumsi terhadap energi listrik.
Peningkatan konsumsi terhadap energi listrik perlu diimbangi dengan pembangunan sarana kelistrikan yang memadai, salah satu upaya yang dilakukan adalah pengembangan gardu induk dan uprating saluran transmisi.

Uprating konduktor ACSR Partridge $135 \mathrm{~mm}^{2}$ dengan kuat hantar arus 400 Ampere menjadi ACCC Lisbon $310 \mathrm{~mm}^{2}$ perlu dilakukan karena arus beban yang lewat pada penghantar mencapai 333,5362 Ampere atau $83,384 \%$ dari kuat hantar arusnya. Uprating konduktor tersebut 
menyebabkan perubahan impedansi urutan positif dan negatif yang sebelumnya 0,2136 + j0,408 $\Omega / \mathrm{km}$ menjadi $0,0896+j 0,41184$ $\Omega / \mathrm{km}$ dan perubahan impedansi urutan nol yang sebelumnya $0,363+j 1,224 \Omega / \mathrm{km}$ menjadi $0,2396+j 1,2355 \Omega / \mathrm{km}$. Perubahan nilai tersebut akan mempengaruhi jangkauan tiap zona proteksi, sehingga perlu dilakukan resetting.

Penelitian yang telah dilakukan sebelumnya adalah perhitungan setting impedansi rele jarak menggunakan perhitungan secara manual [2],[3]. Penelitian lain [4] melakukan analisis setting rele jarak menggunakan Artificial Neural Network. Metode backpropagation Artificial Neural Network digunakan untuk menentukan nilai dari setting rele.

Penelitian ini membahas resetting rele jarak pada saluran GIS Pesanggaran GI Sanur akibat uprating konduktor. Kinerja rele jarak kondisi sebelum dan sesudah resetting akan diuji dan dianalisis dengan memberikan gangguan hubung singkat. Resetting pada rele jarak diharapkan dapat membuat rele mengisolir gangguan dengan tepat dan bekerja sesuai standar yang digunakan.

\section{KAJIAN PUSTAKA}

\subsection{Rele Jarak}

Rele jarak bekerja bergantung pada ratio dari tegangan dan arus, yang dinyatakan dalam impedansi [5]. Rele jarak akan bekerja jika nilai impedansi gangguan lebih besar dibanding nilai impedansi setting.

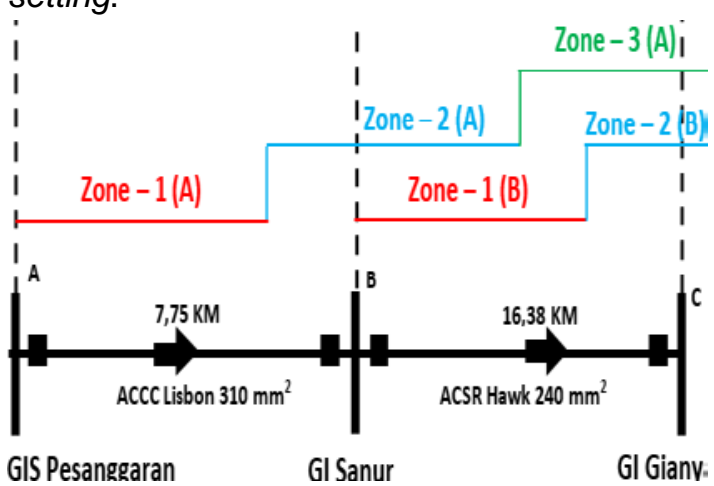

Gambar 1. Zona Proteksi Rele Jarak

\subsection{Zone Reach}

\subsubsection{Zone 1}

Zona 1 merupakan proteksi utama sehingga jangkauannya mengamankan 80 $\%$ dari total panjang saluran utama. Gangguan yang terjadi di daerah Zona 1 maka rele akan bekerja seketika, sehingga tidak dilakukan pengaturan waktu $T_{1}=0$ detik.

[6], [7].

$$
Z_{1}=0,8 \times Z_{\text {line }}
$$

Keterangan :

$Z_{1} \quad=$ Setting impedansi zona 1

$Z_{\text {line1 }}=$ Total impedansi positif $/$ negatif saluran pertama

\subsubsection{Zone 2}

Jangkauan zona 2 harus mengamankan minimum $120 \%$ dari total impedansi saluran pertama dan maksimum tidak melampaui jangkauan zona 1 rele jarak berikutnya. Time delay $=0,4-0,8$ detik [6], [7].

$$
\begin{aligned}
& Z_{\text {min }}=1,2 \times Z_{\text {line } 1} \ldots \ldots \ldots \ldots \ldots \ldots \ldots \ldots \ldots . . .(2) \\
& Z_{\text {min }}=0,8 \times\left(Z_{\text {line } 1}+0,8 \times Z_{\text {line } 2}\right) \ldots \text {..(3) }
\end{aligned}
$$
boleh melebihi dari nilai setting impedansi transformator.

$$
Z_{\text {traf }}=0,8\left(Z_{\text {line } 1}+0,5 \times X_{T}\right) .
$$

Keterangan :

$Z_{\text {2min }}=$ Setting impedansi zona 2 minimum

$Z_{\text {2max }}=$ Setting impedansi zona 2 maximum

$Z_{\text {traf }}=$ Impedansi transformator

$X_{t} \quad=$ Reaktansi transformator

$Z_{\text {line2 }}=$ Total impedansi positif $/$ negatif saluran kedua

Time delay untuk mengisolir gangguan di zona proteksi 2 mengikuti ketentuan sebagai berikut :

$$
T_{2}=\left\{\begin{array}{l}
0,4 \text { s Jika Zona } 2_{\text {max }}>\text { Zona } 2_{\text {min }} \\
0,8 \text { s jika Zona } 2_{\text {min }}>\text { Zona } 2_{\text {max }}
\end{array}\right\}
$$

\subsubsection{Zona 3}

Mengamankan saluran transmisi yang mencakup sampai $2 \mathrm{Gl}$ atau dengan jangkuan $220 \%$. Time delay $=1,2-1,6$ detik [6], [7].

$$
\begin{aligned}
& Z_{3 \min }=1,2 \times\left(Z_{\text {line } 1}+0,8 \times Z_{\text {line } 2 l}\right) \ldots \\
& Z_{3 \min }=0,8 \times\left(Z_{\text {line } 1}+1,2 \times Z_{\text {line } 2 l}\right) \ldots
\end{aligned}
$$

Keterangan : 
$Z_{3 \min }=$ Setting Impedansi zona 3 minimal

$Z_{3 \max }=$ Setting impedansi zona 3 maximal

Time delay untuk mengisolir gangguan yang terjadi di zona proteksi 3 mengikuti ketentuan sebagai berikut :

$T_{3}=\left\{\begin{array}{l}1,2 \text { s Jika Zona } 3_{\text {max }}>\text { Zona } 3_{\text {min }} \\ 1,6 \text { s jika Zona } 3_{\text {min }}>\text { Zona } 3_{\text {max }}\end{array}\right\}$

\subsubsection{Maximum Torque Angle}

Maximum torque angle adalah sudut ketika reach setting mencapai maksimum, dalam artian sudut dari diameter lingkaran mho. Besaran sudut MTA disetting sesuai dengan impedansi urutan positif / negatif penghantar yang diproteksi [8].

\subsubsection{Zero Compensation Factor}

Pada saat gangguan hubung singkat fasa ke tanah, pengukuran impedansi akan mencakup impedansi urutan nol. Hal ini dapat mengakibatkan terjadinya kesalahan pengukuran oleh rele jarak. Diperlukan faktor kompensasi sebagai parameter setting untuk gangguan fasa ke tanah.

$$
K_{0}=\frac{Z_{0}-Z_{1}}{3 Z_{1}}
$$

Keterangan :

$K_{O}=$ Zero Compensation Factor

$Z_{1} \quad=$ Impedansi urutan positif

$Z_{0} \quad=$ Impedansi urutan nol

\section{METODE PENELITIAN}

\subsection{Analisis Data}

Penelitian ini dilakukan di PT. PLN (Persero) Area Pengaturan Beban dan Area Pelaksana Pemeliharaan Bali. Waktu pelaksanaan penelitian ini dimulai pada bulan Agustus - September 2018.

Analisis dalam penelitian ini dilakukan dalam beberapa tahapan sebagai berikut :

1. Melakukan studi literatur.

2. Pengumpulan data kelistrikikan substransmisi sistem Bali yang meliputi : Data Penghantar sistem transmisi $150 \mathrm{kV}$ Bali, Data Transformator, Single Line Diagram Subsistem Bali, dan Data setting proteksi Bay penghantar $150 \mathrm{kV}$
Bali.

3. Melakukan perhitungan impdansi transformator dan saluran transmisi 150 kV Bali.

4. Memodelkan jaringan subsistem transmisi bali.

5. Menghitung resetting rele jarak akibat uprating konduktor dari ACSR Partridge $135 \mathrm{~mm}^{2}$ menjadi ACCC Lisbon 310 $\mathrm{mm}^{2}$ pada saluran transmisi GIS Pesanggaran - GI Sanur.

6. Menguji setting impedansi rele dengan melakukan simulasi gangguan pada sistem sesuai skenario dengan bantuan program komputer.

7. Menganalisis hasil dari simulasi dan membandingkan dengan standar IEEE Standard C37.113-2015.

8. Menarik kesimpulan dari analasis yang telah dilakukan

\section{HASIL DAN PEMBAHASAN}

\subsection{Resetting Rele Jarak}

\subsubsection{Impedansi SUTT $150 \mathrm{kV}$}

Saluran GIS Pesanggaran - GI Sanur setelah uprating, menggunakan penghantar bertipe ACCC Lisbon $310 \mathrm{~mm}^{2}$ dengan panjang penghantar $7,75 \mathrm{~km}$ dan kemampuan hantar arus sebesar 1250 Ampere. Data penghantar ditunjukan pada Tabel 1.

Tabel 1. Data Impedansi SUTT $150 \mathrm{kV}$

\begin{tabular}{|c|c|c|c|c|}
\hline Saluran & $\begin{array}{c}\text { Jenis } \\
\text { Penghantar }\end{array}$ & $\begin{array}{c}\text { Penampang } \\
\left(\mathrm{mm}^{2}\right)\end{array}$ & \begin{tabular}{|c|} 
Total \\
Impedansi \\
Urutan \\
Positif \\
$(\Omega)$ \\
\end{tabular} & \begin{tabular}{|c|} 
Total \\
Impedansi \\
Urutan \\
nol \\
$(\Omega)$ \\
\end{tabular} \\
\hline $\begin{array}{c}\text { GIS } \\
\text { Pesanggaran } \\
\text { - GI Sanur }\end{array}$ & $\begin{array}{c}\text { ACC } \\
\text { Lisbon }\end{array}$ & 310 & $\begin{array}{c}0,6944+ \\
\mathrm{j} 3,19176 \\
\Omega\end{array}$ & $\begin{array}{c}0,9285+ \\
\mathrm{j} 4,7875\end{array}$ \\
\hline $\begin{array}{l}\text { GI Sanur - } \\
\text { GI Gianyar }\end{array}$ & $\begin{array}{c}\text { ACSR / } \\
\text { Hawk }\end{array}$ & 240 & $\begin{array}{r}2,24406+ \\
j 6,50286 \\
\end{array}$ & $\begin{array}{l}4,701 \\
+\mathrm{j} 19.509\end{array}$ \\
\hline
\end{tabular}

Sumber : PT. PLN APP Bali

\subsubsection{Reaktansi Transformator}

Data transformator yang digunakan

di GI Sanur ditunjukkan pada tabel 2.

Tabel 2. Data Transformator 


\begin{tabular}{|c|l|l|l|c|}
\hline $\begin{array}{c}\text { Bay } \\
\text { Trafo }\end{array}$ & \multicolumn{1}{|c|}{ Merk } & \multicolumn{1}{|c|}{ Type } & $\begin{array}{c}\text { Vektor } \\
\text { Group }\end{array}$ & $\begin{array}{c}\text { Imp } \\
\mathbf{( \% )}\end{array}$ \\
\hline Trafo 1 & PAUWELS & ORF 60/275 & YNyn0+d & 12,25 \\
\hline Trafo 2 & UNINDO & TTH-RV & YNyn0(d1) & 12,67 \\
\hline Trafo 3 & UNINDO & TTH-RV & YNyn0(d1) & 12,67 \\
\hline Trafo 4 & UNINDO & $\begin{array}{l}\text { PO60LEC9 } \\
42\end{array}$ & YNyn0 (d1) & 12,19 \\
\hline
\end{tabular}

Sumber : PT. PLN APP Bali

Berdasarkan tabel 2, diketahui bahwa reaktansi terkecil ada ditransformator daya 4 dengan reaktansi sebesar 45,7125 $\Omega$

\subsubsection{Rele Jarak GIS Pesanggaran}

Rele jarak yang digunakan bekerja secara forward dimana rele hanya membaca gangguan yang ada di depannya. Data teknis rele jarak yang digunakan sebagai pengaman penghantar GIS Pesanggaran - GI Sanur ditunjukkan pada tabel 3.

Tabel 3. Data Rele Jarak Pesanggaran Sanur

\begin{tabular}{|c|c|c|c|c|}
\hline $\begin{array}{c}\text { Gardu } \\
\text { Induk }\end{array}$ & Bay & Merk / Type & $\begin{array}{c}\text { Ratio } \\
\text { CT }\end{array}$ & $\begin{array}{c}\text { Ratio } \\
\text { VT }\end{array}$ \\
\hline \multirow{4}{*}{ Pesanggaran } & Sanur 1 & $\begin{array}{c}\text { Alstom Agile / } \\
\text { Micom P443 }\end{array}$ & $2000 / 1$ & $\begin{array}{c}150000 \\
/ 100\end{array}$ \\
\cline { 2 - 5 } & Sanur 2 & $\begin{array}{c}\text { Alstom Agile / } \\
\text { Micom P443 }\end{array}$ & $2000 / 1$ & $\begin{array}{c}150000 / \\
100\end{array}$ \\
\hline
\end{tabular}

Sumber : PT. PLN APP Bali

\subsubsection{Zone Reach}

a. Zona 1

Jangkauan zona 1 dapat dihitung menggunakan persamaan (1) :

$$
\begin{aligned}
Z_{1} & =0,8 \times Z_{11} \\
& =0,55552+\mathrm{j} 2,5536 \Omega \\
Z_{1} & =2,6133 \Omega \\
\theta_{\text {phs }} & =77,7298^{\circ}
\end{aligned}
$$

Waktu yang digunakan untuk mengisolir gangguan $T_{1}=0$ detik.

\section{b. Zona 2}

Jangkauan zona 2 dapat dihitung menggunakan persamaan (2) dan (3) :

$$
\begin{aligned}
Z_{2 \min } & =1,2 \times Z_{\text {line } 1} \\
& =0.83328+\mathrm{j} 3.83 \Omega \\
Z_{2 \min } & =3,919 \Omega \\
\theta_{\text {phs }} & =77.7269^{\circ} \\
Z_{2 \max } & =0,8\left(Z_{\text {line } 1}+0,8 \times Z_{\text {line } 2}\right)
\end{aligned}
$$

$$
\begin{aligned}
& =1.81643+\mathrm{j} 6.44903 \Omega \\
Z_{2 \max } & =6,6999 \Omega \\
\theta_{\text {phs }} & =74,2696^{\circ} \\
& \text { Kemudian dipilih nilai impedansi }
\end{aligned}
$$
terbesar, sehingga nilai yang digunakan adalah $Z_{2 \max }=6,6999 \angle 74,269^{\circ} \Omega$. Time delay untuk Zona 2 adalah $Z_{2 \max }$, sehingga $T_{2}=0,4$ detik karena Zona $2_{\max }>$ Zona $2_{\text {min }}$.

\section{c. Zona 3}

Jangkauan zona 3 dapat dihitung menggunakan persamaan (5) dan (6) :

$$
\begin{aligned}
Z_{3 \min } & =1,2 \times\left(Z_{\text {line } 1}+0,8 \times Z_{\text {line } 2 l}\right) \\
& =2.9899776+\mathrm{j} 10.0707456 \\
Z_{3 \min } & =10.5052 \Omega \\
\theta_{\text {phs }} & =73.464^{\circ} \\
Z_{3 \max } & =0,8\left(Z_{\text {line } 1}+1,2 \times Z_{\text {line } 2}\right) \\
& =2,7098176+\mathrm{j} 8,7961536 \Omega \\
Z_{3 \max } & =9.2041 \Omega \\
\theta_{\text {phs }} & =72.8776^{\circ}
\end{aligned}
$$

Kemudian dipilih nilai impedansi terbesar, sehingga nilai yang digunakan adalah $Z_{3 \min }=10.5052 \angle 73.464^{\circ} \Omega$. Time delay untuk Zona 3 adalah $Z_{3 \min }$, sehingga $T_{3}=1,6$ detik karena Zona $3_{\text {min }}>$ Zona $3_{\text {max }}$.

\subsubsection{Kompensasi Urutan Nol}

Kompensasi urutan nol dapat dihitung menggunakan persamaan (7).

$$
\begin{aligned}
K_{0} & =\frac{Z_{0}-Z_{1}}{3 Z_{1}} \\
& =-0,154041874+\mathrm{j} 0.011274819 \\
K_{0} & =0.66212 \\
\theta_{p h s} & =-1.9517^{\circ}
\end{aligned}
$$

\subsection{Analisis Pengaruh Uprating terhadap Koordinasi Zona Proteksi \\ Perbandingan nilai setting sebelum dan sesudah resetting ditunjukkan pada tabel 4.}

Tabel 4. Perbandingan nilai setting sebelum dan sesudah resetting 


\begin{tabular}{|c|c|c|c|c|c|}
\hline \multirow{3}{*}{ Zona } & \multicolumn{4}{|c|}{ Setting Rele Jarak } & \multirow{3}{*}{$\begin{array}{c}\text { Perubahan } \\
(\%)\end{array}$} \\
\hline & \multicolumn{2}{|c|}{ Sebelum } & \multicolumn{2}{|c|}{ Sesudah } & \\
\hline & $Z_{n}$ & $T_{n}$ & $Z_{n}$ & $T_{n}$ & \\
\hline 1 & 3,55 & 0 & 2,6133 & 0 & 26,3859 \\
\hline 2 & 9,37 & 0,4 & 6,6999 & 0,4 & 28,4963 \\
\hline 3 & 16,32 & 1,6 & 10,5052 & 1,6 & 35,6299 \\
\hline
\end{tabular}

Nilai setting Zona 1 yang awalnya $3,55 \Omega$ mengalami perubahan sebesar $26,3859 \%$ menjadi $2.6133 \Omega$. Nilai setting Zona 2 yang awalnya $9.37 \Omega$ mengalami perubahan sebesar $28.4963 \%$ menjadi $6,6999 \Omega$. Nilai setting Zona 3 yang awalnya $16.32 \Omega$ mengalami perubahan sebesar $35.6299 \%$ menjadi $10.5052 \Omega$. Berdasarkan nilai setting rele jarak sebelum resetting, dapat dibuat diagram seperti pada Gambar 2 menggunakan program bantuan komputer. Garis berwarna merah menunjukan daerah kerja Rele Pesanggaran - Sanur sedangkan garis berwarna hijau adalah daerah kerja rele Sanur - Gianyar.

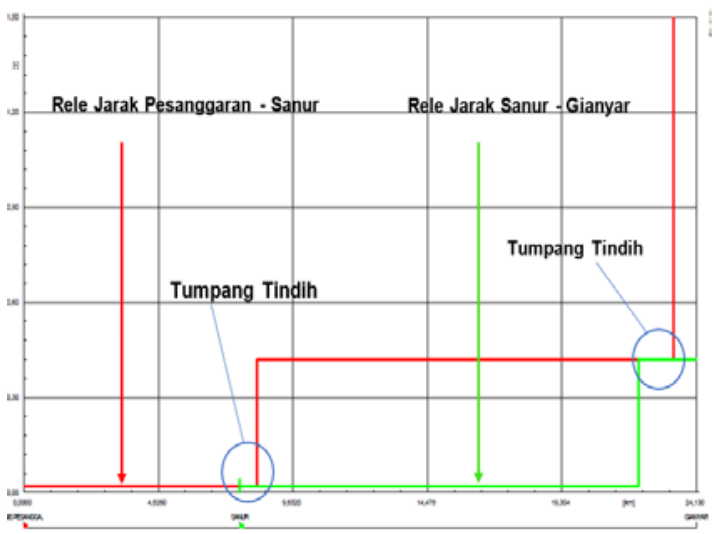

Gambar 2. Time Distance Diagram sebelum resetting

Perbandingan nilai jangkauan setting impedansi terhadap masing masing zona proteksi adalah sebagai berikut :

1. Perbandingan nilai jangkauan zona 1 :

$Z_{\text {perbandingan } 1}=\frac{3.55}{2.6133} \times 80 \%$

$$
=135,8436 \%
$$

2. Perbandingan nilai jangkauan zona 2 :

$$
Z_{\text {perbandingan } 2}=\frac{9.37}{6,6999} \times 120 \%
$$$$
=167.8234 \%
$$

3. Perbandingan nilai jangkauan zona 3 :

$Z_{\text {perbandingan } 3}=\frac{16,32}{10,5052} \times 220 \%$

$$
=341.7736 \%
$$

Berdasarkan Gambar 2, diketahui bahwa setting impedansi kondisi sebelum resetting terjadi tumpang tindih atau overlaps. Overlaps disebabkan perbedaan impedansi penghantar menjadi lebih kecil dengan persentase perubahan seesar $52,52 \%$. Perubahan Impedansi tersebut menyebabkan zona 1 yang seharusnya melindungi $80 \%$ dari total panjang saluran, malah menjadi 135,8436\%. Zona 2 dengan standar jangkauan daerah $120 \%$ menjadi $167,8234 \%$ dan zona 3 dengan standar jangkauan $220 \%$ menjadi 341,7736\%.

Berdasarkan nilai impedansi setelah resetting dapat dibuat time distance diagram rele jarak GIS Pesanggaran arah gianyar kondisi yang ditunjukkan pada gambar 3 . Garis berwarna merah menunjukan daerah kerja Rele Pesanggaran - Sanur sedangkan garis berwarna hijau adalah daerah kerja rele Sanur - Gianyar.

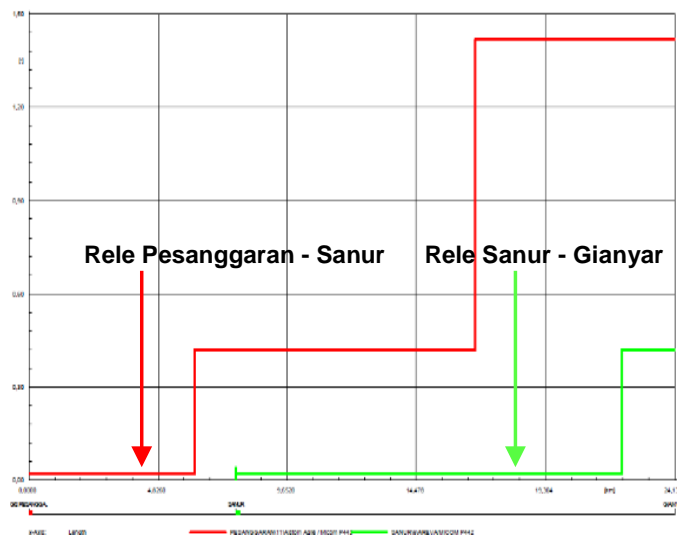

Gambar 3. Time Distance diagram sesudah resetting

Berdasarkan pada gambar 3 diketahui bahwa setelah dilakukan resetting, Jangkauan daerah proteksi sudah baik dan tidak terjadi tumpang tindih. Zona 1 resetting rele jarak sudah memenuhi standar [3] dimana daerah jangkauannya melindungi $80 \%$ panjang saluran utama dengan pengaturan waktu $T_{1}=0$ detik. Jangkauan zona 2 kondisiresetting sudah sesuai dengan standar dimana daerah 
jangkauannya dapat melindungi saluran utama dan tidak melampauijangkauan proteksi zona 1 rele jarak Sanur - Gianyar dengan pengaturan waktu $T_{2}=0,4$ detik. Zona 3 kondisi resetting sudah sesuai dengan standar yang digunakan dengan pengaturan waktu $T_{3}=1.6$ detik.

\subsection{Simulasi Gangguan Hubung Singkat \\ Gangguan hubung singkat} disimulasikan pada $86 \%$ atau $5,8125 \mathrm{~km}$ dari total panjang pada saluran transmisi Pesanggaran - Sanur. Simulasi gangguan hubung singkat ini bertujuan untuk menguji kinerja rele jarak GIS Pesanggaran kondisi sebelum dan sesudah resetting agar sesuai dengan standar yang digunakan saat menangani gangguan yang terjadi pada sistem.

\subsubsection{Gangguan 3 Fasa}

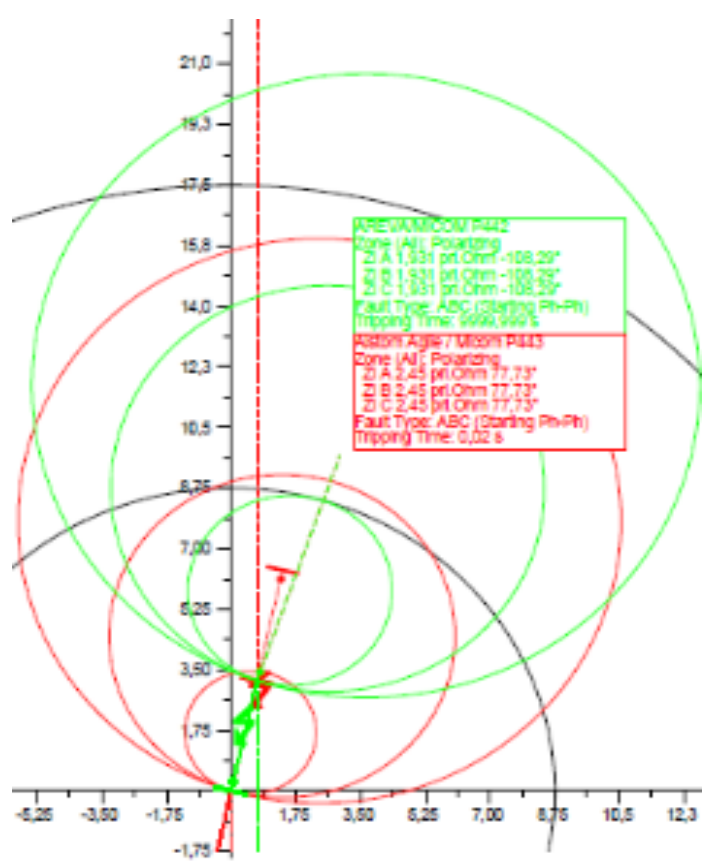

Gambar 4. Kinerja Rele Kondisi sebelum resetting gangguan 3 fasa

Gambar 4 menunjukan kinerja rele jarak Micom P443 pesanggaran - Sanur saat diuji menggunakan gangguan hubung singkat 3 fasa. Garis berwarna merah menunjukan daerah kerja Rele Pesanggaran - Sanur sedangkan garis berwarna hijau adalah daerah kerja rele Sanur - Gianyar.
Rele jarak Pesanggaran - Sanur mendeteksi gangguan pada proteksizona 1 dengan impedansi primer yang terukur sebesar $2,809 \angle 77,73^{\circ} \Omega$ dan waktu trip sebesar 0,02 detik pada $86 \%$ saluran transmisi Pesanggaran - Sanur. Hal ini menunjukan bahwa kinerja rele jarak kondisi sebelum resetting belum sesuai dengan standar. Gangguan pada 86 \% saluran Pesanggaran - Sanur seharusnya dideteksi pada zona 2 dengan waktu trip 0,4 detik.

Rele jarak Micom P442 Sanur Gianyar mendeteksi gangguan sebesar $1,931 \angle-106,29^{\circ} \Omega$ di saluran transmisi Pesanggaran - Sanur. Rele jarak GI Sanur tidak trip atau waktu trip 9999,999 detik karena rele bekerja secara forward, sedangkan gangguan berada di belakang GI Sanur dan diluar dari area jangkauan proteksinya.

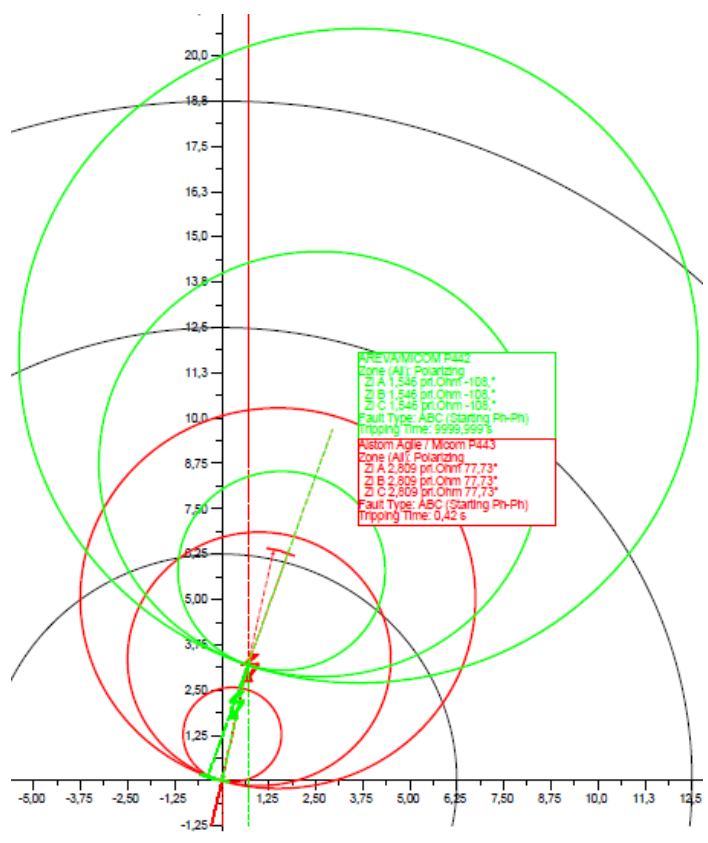

Gambar 5. Kinerja Rele Kondisi Resetting Gangguan 3 fasa

Gambar 5 menunjukan kinerja rele saat terjadi gangguan 3 fasa setelah dilakukan resetting. Garis berwarna merah menunjukan daerah kerja Rele Pesanggaran - Sanur sedangkan garis berwarna hijau adalah daerah kerja rele Sanur - Gianyar. Impedansi yang terukur oleh Rele jarak micom P443 Pesanggaran Sanur saat terjadi gangguan hubung singkat 
3 fasa pada $86 \%$ saluran transmisi Pesanggaran - Sanur 1 adalah 2,809 $\angle 77,73^{\circ} \Omega$. Gangguan yang terjadi kemudian di isolir oleh proteksi zona 2 dalam waktu 0,4 detik. Hal ini menunjukkan bahwa kinerja rele jarak setelah resetting sudah sesuai standar dengan standar IEEE Std C37.1132015.

\section{KESIMPULAN}

Berdasarkan analisis yang telah dilakukan, dapat disimpulkan beberapa hal sebegai berikut :

1. Uprating konduktor menyebabkan Jangkauan proteksi zona 1 dan zona 2 rele jarak GIS Pesanggaran - GI Sanur terjadi tumpang tindih dengan zona 1 dan zona 2 rele GIS Sanur - GI Gianyar. Tumpang tindih yang terjadi akibat perbedaan impedansi menjadi lebih kecil dengan persentase perubahan sebesar $52,52 \%$. Zona 1 yang seharusnya jangkauannya sebesar $80 \%$ dari panjang saluran utama menjadi $135,8436 \%$. Zona 2 dengan standar jangkauan daerah $120 \%$ menjadi $167,8234 \%$ dan zona 3 dengan standar jangkauan $220 \%$ menjadi 341,7736\%.

2. Pada saat simulasi gangguan hubung singkat gangguan pada $86 \%$ saluran Pesanggaran - Sanur, rele jarak Micom P443 pesanggaran - Sanur sebelum resetting mendeteksi gangguan pada zona 1 dan membutuhkan waktu 0,02 detik untuk mengisolir ganguan, hal ini tidak sesuai dengan standar IEEE Std C37.113-2015 dimana gangguan tersebut perlu diisolir pada zona 2 dengan waktu 0,4 detik.

3. Jangkauan proteksi menggunakan nilai impendansi resetting yaitu pada zona 1 $\left(Z_{1 s)}\right.$ sebesar $3,4843 \angle 977,726^{\circ} \Omega$, zona $2\left(Z_{2 s}\right)$ sebesar $8,9109 \angle 74.269^{\circ} \Omega$, dan zona $3 \quad\left(Z_{3 s}\right)$ sebesar 13.9712 $\angle 73.4699^{\circ} \Omega$ menunjukan koordinasi proteksi sudah baik dan tidak terjadi Overlaps.

4. Pada saat simulasi gangguan hubung singkat pada $86 \quad \% \quad$ saluran
Pesanggaran - Sanur, kinerja rele jarak Micom P443 pesanggaran - Sanur menggunakan nilai impendansi setelah resetting bekerja sesuai standar IEEE Std C37.113-2015 dimana gangguan sudah terdeteksi di zona 2 dan membutuhkan waktu 0,4 detik untuk mengisolir gangguan.

\section{DAFTAR PUSTAKA}

[1]. PT. PLN. 2015. Rencana Usaha Penyediaan Tenaga Listrik (RUPTL) 2018-2027. Jakarta: PT PLN (Persero). p. $442-452$.

[2]. Sudrajat, Rhamandita; Saodah, Siti; Waluyo, Waluyo. Analisis Penalaan Rele Jarak sebagai Proteksi Utama pada Saluran Udara Tegangan Tinggi 150 kV Bandung SelatanCigereleng. Reka Elkomika, 2014, 2.1.

[3]. Supriana, Sang Kompyang; Arjana, Ig Dyana; Amrita, A. A. N. Studi Pengaruh Uprating Saluran Transmisi Tegangan Tinggi $150 \mathrm{kV}$ Terhadap Setting Rele Jarak Antara GI Kapal-GI Padang Sambian-GI Pesanggaran. Jurnal IImiah SPEKTRUM, 2014, 1.1: 59-64.

[4]. Hadianto, Alfian; Arjana, I. Gede Dyana; Setiawan, Widyadi. Studi Perhitungan Relay Jarak Pada Saluran Double Circuit Dengan Single Conductor Antara Gi Kapal-Gi Pemecutan Kelod Menggunakan Artificial Neural Network (Ann). Majalah IImiah Teknologi Elektro, 2016, 15.2: 59-66.

[5]. Bakshi, U. A.; Bakshi, M. V. Protection And Switchgear. Technical Publications, 2009: 4-1.

[6]. MiCOM P40 Agile P441 P442 P444 Technical Manual Platform Software Version: 61 \& 70 Publication Reference: P44x/EN M/H96

[7]. PT. PLN. 2015. Workshop Setting dan Scanning Sistem Proteksi. Gandul :P3B Jawa Bali.

[8]. Thompson, Michael J.; Heidfeld, Daniel L. Transmission line setting calculations-beyond the cookbook. In: Protective Relay Engineers, 2015 68th 
Annual Conference for. IEEE, 2015. p. 850-865.

[9]. IEEE standard, C37.113-2015. IEEE Guide for Protective Relay Applications to Transmission Lines. 